\title{
Toward an Ecological Perspective of Interethnic Ideologies: Moderation Effects of Ethnic Density on Relationships between Interethnic Ideologies and Intergroup Bias
}

\author{
Dmitry S. Grigoryev, Tomas Jurcik, Anastasia A. Batkhina*, \\ Dmitrii I. Dubrov \\ National Research University Higher School of Economics, Moscow, Russian Federation \\ *Corresponding author. E-mail: batkhina.anastasia@gmail.com
}

\begin{abstract}
Introduction. In this exploratory study, we examined several interethnic ideologies held by individuals (assimilation, colorblindness, multiculturalism, and polyculturalism) from a social ecological perspective. We examined moderation effects of neighborhood ethnic density (ED) on relationships between interethnic ideologies and intergroup bias towards various minority ethnic groups in the Russian context. Intergroup bias was assessed as a composite score of bias toward four ethnic groups who have different cultural distances from the Russian mainstream population: Chechens, Belarusians, Uzbeks, and Chinese.
\end{abstract}

Method. We obtained a gender balanced sample of ethnic Russians from the Central Federal District of Russia ( $N=359$ ) comprising of $47 \%$ women and $53 \%$ men. The measures were used in a Russian translation by an adaptation using the back-translation and cognitive interviews. Multiple regression analysis was used to test the relationships.

Results. The results showed that high perceived neighborhood non-Russian ED weakened negative relations between intergroup bias and ideologies that purportedly accept cultural diversity (multiculturalism and polyculturalism). On the other hand, for interethnic ideologies those purportedly reject cultural diversity, high perceived neighborhood non-Russian ED weakened the positive relations between intergroup bias and assimilation and strengthened the negative relations between intergroup bias and colorblindness.

Discussion. The pattern of results suggests that the relationship between attitudes and intergroup bias may change based on the perceived ethnic composition of the local area and frequency of contacts. Although our findings are relatively novel they support the emerging view that attitudes and intergroup relations need to be studied from a social ecological context. 


\section{Keywords}

ethnic density, interethnic ideologies, intergroup bias, assimilation, colorblindness, multiculturalism, polyculturalism, intercultural relations, ethnic diversity, generalized prejudice

\section{Highlights}

- High perceived neighborhood non-Russian ethnic density weakened negative relations between intergroup bias and multiculturalism and polyculturalism.

- High perceived neighborhood non-Russian ethnic density weakened the positive relations between intergroup bias and assimilation.

- High perceived neighborhood non-Russian ethnic density strengthened the negative relations between intergroup bias and colorblindness.

\section{For citation}

Grigoryev D. S., Jurcik T., Batkhina A. A., Dubrov D. I. Toward an Ecological Perspective of Interethnic Ideologies: Moderation Effects of Ethnic Density on Relationships between Interethnic Ideologies and Intergroup Bias. Rossiiskii psikhologicheskii zhurnal - Russian Psychological Journal, 2018, Thematic Issue 1 (Vol. 15, no. 2/1), pp. 117-130. DOI: 10.21702/rpj.2018.2.1.7

Original manuscript received 14.08.2018

\section{Introduction}

In recent years the study of intergroup relations is actively spurred on by the acute need to manage an increasingly culturally and ethnically diverse society. The creation of a social climate where all ethnic groups might harmoniously coexist is the central challenge for many communities today [e.g., 1]. This need is especially important for culturally and ethnically diverse societies such as Russia. Should we emphasize similarities and common ground or, conversely, recognize that there are important differences between groups? What interethnic ideology and politics of intercultural relations in Russia would be most successful in reducing intergroup prejudice and discrimination? In the literature there are contradictory results about the role of each of the interethnic ideologies in pathways to positive intergroup relations and more research is needed to understand and recognize the mechanisms and consequences of interethnic ideologies [2, 3]. In addition, a social ecological context is frequently overlooked in the psychological acculturation literature [4]. Although there is some limited research on perceived ethnic diversity [e.g., 5] and perceived ethnic density of minority immigrant groups and discrimination [e.g., 6] we are not aware of research on intergroup bias that has examined minority ethnic density from the perspective of majority group members. In this study, we thus addressed 
interethnic ideologies from an ecological perspective by considering moderation effects of neighborhood ethnic density (ED) on relations between interethnic ideologies and intergroup bias in the Russian context.

\section{Interethnic Ideologies}

Interethnic ideologies have both a socially constructed superstructure (the network that creates and transmits the social representation of an ordered society) and a motivational substructure (epistemic, existential, and relational motives) reflecting shared belief systems or prescription about how society should be structured, while providing a cognitive framework in which to interpret the social environment [7]. At the core of each of the interethnic ideologies lie different principles of categorization that divide the human social world into various groups [see 8]. These different principles of categorization underlie interethnic ideologies, policies, and individual and group attitudes: (1) assimilation assumes that there should be a common group, and minority groups must correspond to the main part of society by adopting a mainstream culture while rejecting their own (i.e., recategorization $\rightarrow$ one group $\rightarrow$ assimilation); (2) colorblindness assumes that intergroup relations can be improved by ignoring the differences between groups (i.e., decategorization $\rightarrow$ no group $\rightarrow$ colorblindness); (3) multiculturalism recognizes differences between groups and assumes that maintenance of this diversity is important (i.e., salient categorization $\rightarrow$ multiple groups $\rightarrow$ multiculturalism); and (4) polyculturalism, which assumes a strong connection between all groups and pays less attention to the boundaries between them; put simply, all cultures are not isolated systems but are the product of intergroup interaction [for a review, see 8, 2, 3, 9]. This taxonomy of the interethnic ideologies is presented in Table 1.

Table 1. Taxonomy of the Interethnic Ideologies

\begin{tabular}{|c|c|c|c|}
\hline \multicolumn{4}{|c|}{ Interethnic ideologies } \\
\hline \multicolumn{2}{|c|}{ Rejection of cultural diversity } & \multicolumn{2}{|c|}{ Acceptance of cultural diversity } \\
\hline $\begin{array}{c}\text { Assimilation } \\
\text { (one group } \\
\text { with a common } \\
\text { mainstream } \\
\text { culture; eliminating } \\
\text { minority group } \\
\text { memberships) }\end{array}$ & $\begin{array}{l}\text { Colorblindness } \\
\text { (no groups, only } \\
\text { unique people; } \\
\text { ignoring group } \\
\text { memberships) }\end{array}$ & $\begin{array}{l}\frac{\text { Multiculturalism }}{\text { (plurality of }} \\
\text { different groups; } \\
\text { acknowledging } \\
\text { and valuing } \\
\text { group } \\
\text { memberships) }\end{array}$ & $\begin{array}{l}\text { Polyculturalism } \\
\text { (plurality of } \\
\text { interconnected } \\
\text { groups; } \\
\text { acknowledging } \\
\text { group memberships } \\
\text { with valuing } \\
\text { interconnection } \\
\text { between groups) }\end{array}$ \\
\hline
\end{tabular}




\section{Neighborhood Ethnic Density}

The interethnic processes can be conceptualized at different levels, such as, describing a neighborhood, a region or even country, each of which represents a special social community climate, etc. [for a review, see 10]. Despite the fact that these processes have been thoroughly studied at the macro level, the investigation of factors that affect these processes in a local, neighborhood environment has begun relatively recently $[6,11]$. Such neighborhood factors include ED understood as the proportion of ethnic minority representatives living in a particular local area [12]. Ethnic or linguistic density can be studied using two main approaches: objectively (e.g., measured through census data) and subjectively (perceived individually), with recent studies showing that both types are moderately correlated $[13,14]$. In other words, individuals seem to have a fairly accurate perception of the ethnolinguistic composition of their neighborhood. Although there are some inconsistent findings, research has shown that ED has been related to less prejudice, more social support, as well as better physical and mental health outcomes (protective ED-health associations are often referred to as the "ethnic density effect" [e.g., 6, 12, 13, 15]. In recent years there has been a developing interest in considering the moderating effects of ED on the acculturation process [e.g., 6, 13, 16]. Concurrently, research examining ethnic density and the interethnic attitudes of the majority group remains unexplored. Thus, it is possible that perceptions of co-ethnic concentration, and opportunities for interethnic contact, may influence the types of attitudes that the majority cultural group holds. ED effects in Russia, an increasingly diverse society with a very high rate of migration, have yet to be understood.

\section{Present Study}

In the present exploratory study, we examined models of relationships between assimilation, colorblindness, multiculturalism, polyculturalism and intergroup bias with moderation effects of perceived non-Russian ED and frequency of contacts. Assessment of generalized prejudice was based on two assumptions: (1) the prejudice towards one specific outgroup is, for the most part, associated with prejudice towards other outgroups [17]; and (2) attitudes towards ethnic groups are likely to differ depending on the specific group, and thus studying broad attitudes towards the groups in general will obfuscate such variance [18]. We considered four ethnic groups which have different cultural distances from the Russian mainstream population: Chechens, Belarusians, Uzbeks, and Chinese. We composed the intergroup bias outcome to reflect blatant and subtle bias towards each of the considered groups using measures of willingness for intergroup contact and endorsement of discrimination in the socioeconomic domain as manifest variables; both of these latter variables are informative 
aspects of intergroup bias since they reflect prejudice and negative attitudes towards ethnic outgroups [e.g., 19, 20, 21]. Finally, we added the frequency of contacts to separate the ED effect from the effect of intergroup contacts, which commonly reduces prejudice [e.g., 22, 23].

\section{Method}

Sample. The total sample comprised 359 ethnic Russians residing in the Central Federal District of Russia. It included 167 women (46,5\%) and 192 men (53,5\%), aged from 16 to 68 years $(M=33,9, S D=11,9) ; 79$ participants $(22 \%)$ were students.

Measures. All measures which did not have a Russian translation were adapted by back-translation and cognitive interviews with the think-aloud technique [24]. All measures included or were adapted to use a 9-point Likert scale, so that higher scores indicate stronger endorsement of the concept. Internal consistency coefficients for the current study were generally adequate to excellent (Cronbach's alpha (a) ranging from 0,62 to 0,94; the average value was 0,81$)$ and are provided in brackets.

\section{Antecedent Variables}

Interethnic ideologies. Three interethnic ideologies, colorblindness, multiculturalism, and polyculturalism were assessed with 5 items [9] and 5 items to assess for assimilation [8]. Sample items included "There should be no cultural differences between ethnic groups; there should be a single group and people should maintain the culture of the majority of the country's population," (assimilation, $a=0,75$ ), "All human beings are individuals, and therefore race and ethnicity are not important," (colorblindness, $a=0,83$ ), "There are differences between racial and ethnic groups, which are important to recognize," (multiculturalism, $a=0,63$ ), and "There are many connections between different cultures" (polyculturalism, $a=0,78$ ).

Frequency of contacts. We used 3 items assessing frequency of interethnic contacts [23]. A sample item was "How many people from another ethnic group in Russia do you know personally?" $(a=0,85)$.

Perceived ethnic density. A 4 item scale was used to assess perceived neighborhood ethnic density [13]. We revised the items to assess participant perceptions about the proportion of non-Russians residing in their local areas [8]. For example, participants were asked in Russian to think of their local area (15-20 minutes walking distance from their home) and to estimate "What proportion of all the people in this local area is of other [i.e., non-Russian] ethnic groups?" $(a=0,76)$.

\section{Outcome Variables}

Blatant bias. A 5 item scale assessed blatant bias towards each of the considered ethnic groups [19]. Sample items included "I would agree to live in 
the same neighborhood with an Uzbek," and "I am willing to invite an Uzbek to a social event at my home" (for Chechens $a=0,92$; for Belarusians $a=0,94$; for Uzbeks $a=0,93$; for Chinese $a=0,90$ ).

Subtle bias. We used 6 items for each considered group asking for endorsement of behaviors that reflect discrimination of immigrants in the workspace, labor market, rental housing sectors, and other relevant socioeconomic domain according to literature [e.g., 19, 20]. Sample items included endorsing "Paying Chechens lower wages than natives, provided equal qualifications and level of education," and "The lack of career prospects for Chechens" (for Chechens $a=0,80$; for Belarusians $a=0,62$; for Uzbeks $a=0,86$; for Chinese $a=0,83$ ).

\section{Data Analysis}

Using SPSS v. 22, we conducted data screening including checking for outliers and missing data. We used the lavaan R package [25] to construct the measurement model with eight latent factors and one second-order factor: intergroup bias was set to load onto specific group bias, which was composed of blatant and subtle bias towards each considered group (i.e., Chechens, Belarusians, Uzbeks, and Chinese). We checked the fit of this model by applying confirmatory factor analysis (CFA). Estimation of the model was carried out with the use of robust statistics chi-square (Satorra-Bentler corrections MLM estimator). We employed commonly recommended global fit measures: $\mathrm{CFI}>0,90$ and RMSEA $<0,08$ [26].

We tested moderation effects in the regression models applying a test of the difference between the simple slopes for low ( -1 SD below the mean) and high (+1 SD above the mean) levels of frequency of contacts and perceived ethnic density. This method is more accurate than a test of the interaction term in the full regression model [27]. To estimate the moderation effects we used the Model 2 template of PROCESS macro v.2.15 for SPSS [28].

\section{Results}

Preliminary Analysis

The data had no outliers and missing values. The measurement model had an acceptable global fit: $\chi^{2}(330, N=359)=699,22, p<0,001 ; C F I=0,906$; RMSEA $[90 \% \mathrm{Cl}]=0,056[0,051,0,061]$. Descriptive statistics including means, standard deviations, and bivariate correlations are presented in Table 2.

The results for the moderation models and simple slopes are shown in Table 3 and Figure 1. The explained variation of intergroup bias ranged from $7 \%$ to $14 \%$ across the tested models. The main effects showed that frequency of contacts, colorblindness, multiculturalism, and polyculturalism negatively predicted intergroup bias; assimilation positively predicted intergroup bias. 
Additionally, frequency of contacts weakened the relation between intergroup bias and interethnic ideologies for all tested moderating variable conditions. Furthermore, high perceived non-Russian ED strengthened the negative relation between intergroup bias and colorblindness, but for assimilation, non-Russian ED weakened the positive relation with intergroup bias. Although, effect sizes for these changes were remarkably small. Also, high perceived non-Russian ED weakened the negative relation between intergroup bias and polyculturalism and made the relationship between intergroup bias and multiculturalism non-significant.

Table 2. Descriptive Statistics and Bivariate Correlations between the Variables $(\mathrm{N}=359)$

\begin{tabular}{llcccccc}
\hline & $\mathbf{M ~ ( S D )}$ & $\mathbf{1}$ & $\mathbf{2}$ & $\mathbf{3}$ & $\mathbf{4}$ & $\mathbf{5}$ & $\mathbf{6}$ \\
\hline 1. Intergroup bias & $2,81(1,51)$ & & & & & & \\
\hline 2. Assimilation & $5,47(1,79)$ & 0,26 & & & & & \\
\hline 3. Colorblindness & $4,10(2,17)$ & $-0,32$ & 0,06 & & & & \\
\hline 4. Multiculturalism & $7,32(1,13)$ & $-0,12$ & $-0,02$ & $-0,18$ & & & \\
\hline 5. Polyculturalism & $7,33(1,29)$ & $-0,33$ & 0,06 & 0,09 & 0,37 & & \\
\hline 6. Frequency of contacts & $5,48(2,13)$ & $-0,17$ & $-0,01$ & 0,08 & 0,04 & 0,13 & \\
\hline $\begin{array}{l}\text { 7. Perceived ethnic } \\
\text { density }\end{array}$ & $3,80(1,65)$ & 0,02 & $-0,03$ & 0,01 & 0,10 & 0,05 & 0,32 \\
\hline
\end{tabular}

Note. All correlations with absolute value greater than 0,10 are significant $(p<0,05)$.

\section{Simple Slopes Analysis}

Table 3. The Results for the Moderation Models between Interethnic Ideologies, Perceived Non-Russian Ethnic Density and Frequency of Interethnic Contact for Intergroup Bias ( $\mathrm{N}=359$ )

$\beta$

\begin{tabular}{|c|c|c|}
\hline \multicolumn{3}{|c|}{ Model $1\left(R^{2}=0,11\right)$} \\
\hline \multicolumn{3}{|c|}{ Main effects } \\
\hline \multicolumn{2}{|c|}{ Assimilation } & $0,27^{* * *}$ \\
\hline \multicolumn{2}{|l|}{ FC } & $-0,20 * * *$ \\
\hline \multicolumn{2}{|l|}{ PED } & 0,10 \\
\hline \multicolumn{3}{|c|}{ Simple slope analysis } \\
\hline \multirow{2}{*}{ - LOW PED } & Low FC & $0,35^{* * *}$ \\
\hline & High FC & $0,28^{* *}$ \\
\hline \multirow{2}{*}{ High PED } & Low FC & $0,26^{* *}$ \\
\hline & High FC & $0,19^{* *}$ \\
\hline
\end{tabular}




\section{Model $2\left(R^{2}=0,13\right)$}

Main effects

\begin{tabular}{|c|c|c|}
\hline \multicolumn{2}{|c|}{ Colorblindness } & $-0,30^{* * *}$ \\
\hline \multicolumn{2}{|l|}{ FC } & $-0,17^{* *}$ \\
\hline \multicolumn{2}{|l|}{ PED } & 0,07 \\
\hline \multicolumn{3}{|c|}{ Simple slope analysis } \\
\hline \multirow{2}{*}{ - LOW PED } & Low FC & $-0,28 * *$ \\
\hline & High FC & $-0,25^{*}$ \\
\hline \multirow{2}{*}{ - High PED } & Low FC & $-0,36^{* *}$ \\
\hline & High FC & $-0,32^{* * *}$ \\
\hline
\end{tabular}

\section{Model $3\left(R^{2}=0,07\right)$}

\begin{tabular}{|c|c|c|}
\hline \multicolumn{3}{|l|}{ Main effects } \\
\hline \multicolumn{2}{|c|}{ Multiculturalism } & $-0,14^{* *}$ \\
\hline \multicolumn{2}{|l|}{$\mathrm{FC}$} & $-0,21^{* * *}$ \\
\hline \multicolumn{2}{|l|}{ PED } & 0,08 \\
\hline \multicolumn{3}{|c|}{ Simple slope analysis } \\
\hline \multirow{2}{*}{ — LOW PED } & Low FC & $-0,30 * *$ \\
\hline & High FC & $-0,22^{*}$ \\
\hline \multirow{2}{*}{ - High PED } & Low FC & $-0,07$ \\
\hline & High FC & 0,01 \\
\hline \multicolumn{3}{|c|}{ Model $4\left(R^{2}=0,14\right)$} \\
\hline \multicolumn{3}{|l|}{ Main effects } \\
\hline \multicolumn{2}{|c|}{ Polyculturalism } & $-0,32^{* * *}$ \\
\hline \multicolumn{2}{|l|}{ FC } & $-0,17^{* *}$ \\
\hline \multicolumn{2}{|l|}{ PED } & 0,08 \\
\hline \multicolumn{3}{|c|}{ Simple slope analysis } \\
\hline \multirow{2}{*}{ — LOW PED } & Low FC & $-0,42^{* * *}$ \\
\hline & High FC & $-0,38^{* * *}$ \\
\hline \multirow{2}{*}{$\begin{array}{l}\text { High } \\
\text { PED }\end{array}$} & Low FC & $-0,26^{* *}$ \\
\hline & High FC & $-0,22^{* *}$ \\
\hline
\end{tabular}

Note. $\mathrm{FC}=$ Frequency of contacts; $\mathrm{PED}=$ Perceived ethnic density. ${ }^{* * *} p<0,001,{ }^{* *} p<0,01,{ }^{*} p<0,05$ 

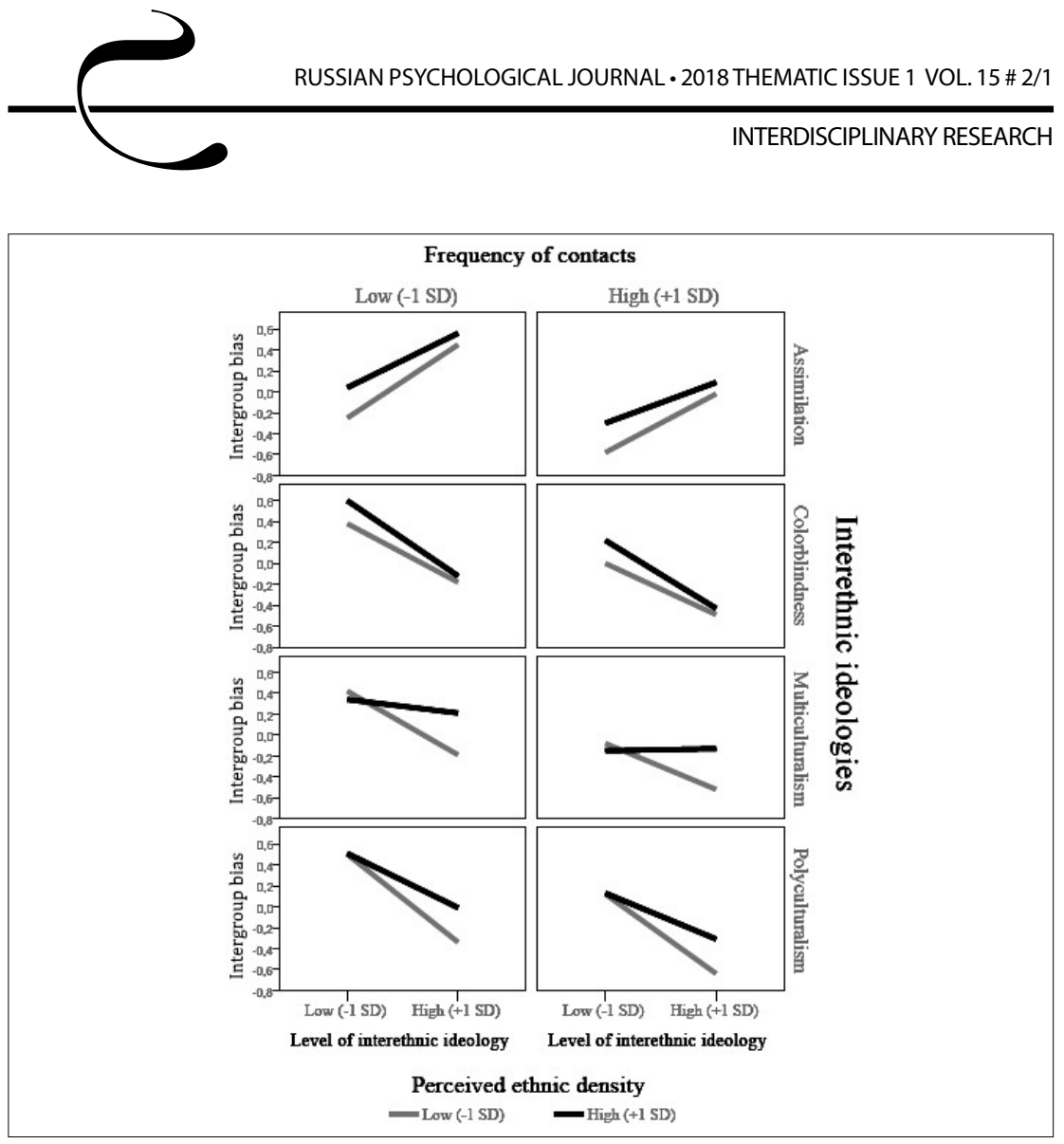

Figure 1. The simple slopes examining the relations between interethnic ideologies, perceived non-Russian ethnic density and frequency of interethnic contact for intergroup bias

\section{Discussion}

In this study, we investigated the moderation effects of neighborhood ED on relationships between assimilation, colorblindness, multiculturalism, polyculturalism and intergroup bias in the Russian context. In the case of ideologies that purportedly reject cultural diversity, we found negative (colorblindness) and positive (assimilation) relations with bias, respectively. We also found that high non-Russian ED weakened protective effects against intergroup bias for ideologies that purportedly accept cultural diversity (multiculturalism and polyculturalism). Moreover, while the negative multiculturalism-bias relation lost significance in the high ED condition, in contrast the polyculturalism-bias relationship was robust for those living in high non-Russian ED neighborhoods. Perhaps this finding occurred because polyculturalism is associated with more interest and appreciation for diversity and comfort with differences [9]. 
Some of our findings with ethnic density may be paradoxical. Indeed, beliefs in cultural diversity (i.e., multiculturalism and polyculturalism) were associated with less intergroup bias, but it is noteworthy that this relation seemed more pronounced in neighborhoods perceived to have a smaller proportion of minority members. Perhaps this finding speaks to some of the challenges with trust and cohesion that occur with increasing ethnic diversity [e.g., 1]. Although we found no correlation between ED and intergroup bias, ED may interact with individual attitudes and beliefs [e.g., 6]. In addition, our results confirmed the well-established finding that intergroup contact is associated with reduced prejudice [e.g., 22], and showed that non-majority group ED is associated with more contact with minority members.

\section{Implications}

Our patterns of results suggest that the relationship between attitudes and prejudice may change based on the perceived ethnic composition of the local area and frequency of interethnic contacts. The current study is one of the first studies to explore the interactions between ED and interethnic ideologies in the Russian population. It adds to the mounting evidence that attitudes or individual ideologies need to study in social context to better understand the complexity of psychological phenomena, and may help explain some of the contradictory findings in cross-cultural research which neglect to account for such (real or perceived) ecological contexts [e.g. 6, 29].

\section{Limitations and Further Research}

There are some limitations of the study and alternative explanations. Acceptance of cultural diversity (i.e., less bias) in the case of high levels of multiand poly-culturalism may be due the features of design of this study; perhaps such a bias would be less pronounced in studies that examine implicit attitudes. Alternatively, the results may be affected by authoritarian attitudes. Those high on authoritarianism tend to overestimate diversity (or minority ethnic density) of their environment or live in neighborhoods with an objectively smaller minority presence, perceive more threat, and negatively relate to diversity [e.g., 9, 26]. Since the study is correlational and may be affected by unmeasured confounds, cause and effect between the measured variables cannot be disentangled.

In our study, we measured perceived non-Russian ED as perceived by the majority using revised items, which is not typical, given that most research uses perceived ED of the participant's group [e.g., 6, 13, 14], and it is less clear how the current adaptation is associated with objective or census-tract ED. Nevertheless, our findings support the idea that psychological attitudes are more meaningful when studied in social ecological context [4]. 
Future studies may benefit from use of a longitudinal design in well as objective measures of ED in combination with subjective ones [e.g., 13]. Other variables of interest may include authoritarian attitudes, perceived threat, intergroup anxiety, and national identification. Addressing these antecedents of intergroup bias from an ecological perspective may lead to a better understanding of intergroup attitudes and perhaps resolve some existing unanswered questions in the field.

\section{Summary and Conclusions}

The current exploratory study examined relations between intergroup bias, interethnic ideologies, and local area ED in an ethnically Russian sample. Participants reported less intergroup bias if they endorsed a greater amount of interethnic contact. Most interethnic ideologies (multiculturalism, polyculturalism, and colorblindness) were also associated with less bias, although the reverse was found for assimilation. Perhaps paradoxically, a greater perceived concentration of minority members in the participants' neighborhoods may have weakened the protective effects of ideologies focused on recognizing cultural diversity. Our findings may highlight some of challenges and opportunities associated with changing demographics, and shed further light on how belief systems may interact with social ecology. Future researchers will likely have a more meaningful story to tell if they study social psychological phenomena in context.

\section{Acknowledgments}

The article was prepared within the framework of the Basic Research Program at the National Research University Higher School of Economics (HSE) and supported within the framework of a subsidy by the Russian Academic Excellence Project '5-100'.

\section{References}

1. Putnam R. D. E Pluribus Unum: Diversity and Community in the Twenty-first Century The 2006 Johan Skytte Prize Lecture. Scandinavian Political Studies, 2007, Vol. 30, pp. 137-174. DOI: 10.1111/j.1467-9477.2007.00176.x

2. Pedersen A., Paradies Y., Barndon A. The consequences of intergroup ideologies and prejudice control for discrimination and harmony. Journal of Applied Social Psychology, 2015, Vol. 45, pp. 684-696. DOI: 10.1111/jasp.12330

3. Rattan A., Ambady N. Diversity ideologies and intergroup relations: An examination of colorblindness and multiculturalism: Diversity ideologies and intergroup relations. European Journal of Social Psychology, 2013, Vol. 43, pp. 12-21. DOI: 10.1002/ejsp.1892

4. Jurcik T., Yakobov E., Ahmed R., Solopieieva-Jurcikova L., Sunohara M., Ryder A. Social Ecology and the Recontextualization of Acculturation: 
Exploring the Psychological Role of Ethnic Density. In: J. Merton (ed.) Acculturation: Psychology, Processes, and Global Perspectives. Hauppauge, NY: Nova Science, 2014, pp. 97-114.

5. van Assche J., Roets A., Dhont K., van Hiel A. The association between actual and perceived ethnic diversity: The moderating role of authoritarianism and implications for outgroup threat, anxiety, and mistrust. European Journal of Social Psychology, 2016, Vol. 46, pp. 807-817. DOI: 10.1002/ejsp.2211

6. JurcikT., Ahmed R., Yakobov E., Solopieieva-Jurcikova L., Ryder A. G. Understanding the role of ethnic density effect: Issues of acculturation, discrimination and social support. Journal of Community Psychology, 2013, Vol. 41, pp. 662-678. DOI: $10.1002 /$ jcop. 21563

7. Badea C. Group Ideologies. In: F. M. Moghaddam (ed.) The SAGE Encyclopedia of Political Behavior. London, UK: SAGE Publications, 2017, pp. 46-47.

8. Grigoryev D., Batkhina A., Dubrov D. Assimilationism, multiculturalism, colorblindness, and polyculturalism in the Russian Context. Cultural-Historical Psychology, 2018, Vol. 14, pp. 53-65. DOI: $10.17759 /$ chp.2018140206

9. Rosenthal L., Levy S. R. The relation between polyculturalism and intergroup attitudes among racially and ethnically diverse adults. Cultural Diversity and Ethnic Minority Psychology, 2012, Vol. 18, pp. 1-16. DOI: $10.1037 / a 0026490$

10. Berry J. W. Contexts of acculturation. In: D. Sam \& J. W. Berry (ed.) The handbook of acculturation psychology. Cambridge, UK: Cambridge University Press, 2006, pp. 27-42.

11. Birman D., Trickett E., Buchanan R. M. A tale of two cities: Replication of a study on the acculturation and adaptation of immigrant adolescents from the former Soviet Union in a different community context. American Journal of Community Psychology, 2005, Vol. 35, pp. 87-101. DOI: $10.1007 /$ s10464-005-1891-y

12. Shaw R. J., Atkin K., Bécares L., Albor C. B., Stafford M., Kiernan K. E., Nazroo J. Y., Wilkinson R. G., Pickett K. E. Impact of ethnic density on adult mental disorders: Narrative review. British Journal of Psychiatry, 2012, Vol. 201, pp. 11-19. DOI: 10.1192/bjp.bp.110.083675

13. Jurcik T., Yakobov E., Solopieieva-Jurcikova L., Ahmed R., Sunohara M., Ryder A. G. Unraveling ethnic density effects, acculturation and adjustment:The case of Russian-speaking immigrants from the former Soviet Union. Journal of Community Psychology, 2015, Vol. 43, pp. 628-648. DOI: $10.1002 / j c o p .21708$

14. Stafford M., Bécares L., Nazroo J. Objective and perceived ethnic density and health: 111 findings from a UK general population survey. American Journal of Epidemiology, 2009, Vol. 170, pp. 484-493. DOI: 10.1093/aje/kwp160

15. Bécares L., Shaw R., Nazroo J., Stafford M., Albor C., Atkin K., ... Pickett K. Ethnic Density Effects on Physical Morbidity, Mortality, and Health Behaviors: 
A Systematic Review of the Literature. American Journal of Public Health, 2012, Vol. 102, pp. 33-66. DOI: 10.2105/AJPH.2012.300832

16. Miller A. M., Birman D., Zenk S., Wang E., Sorokin O., Connor J. Neighborhood immigrant concentration, acculturation, and cultural alienation in former Soviet 107 immigrant women. Journal of Community Psychology, 2009, Vol. 37, pp. 88-105. DOI: $10.1002 /$ jcop.20272

17. Hodson G., Maclnnis C. C., Busseri M. A. Bowing and kicking: Rediscovering the fundamental link between generalized authoritarianism and generalized prejudice. Personality and Individual Differences, 2017, Vol. 104, pp. 243-251. DOI: 10.1016/j.paid.2016.08.018

18. Satherley N., Sibley C. G. A Dual Process Model of attitudes toward immigration: Predicting intergroup and international relations with China. International Journal of Intercultural Relations, 2016, Vol. 53, pp. 72-82. DOI: 10.1016/j.ijintrel.2016.05.008

19. Grigoryev D., van de Vijver F., Batkhina A. Discordance of acculturation attitudes of the host population and their dealing with immigrants. Journal of Intercultural Communication Research, 2018. DOI: 10.1080/17475759.2018.1497678

20. Mallender J., Gutheil M., Heetman A., Griffiths D., Carlberg M., Marangozov R. Discrimination of migrant workers at the workplace. Luxembourg, Luxembourg: Publications Office, 2014. 64 p.

21. Wang C. S., Kenneth T., Ku G., Galinsky A. D. Perspective-Taking Increases Willingness to Engage in Intergroup Contact. PLOS ONE, 2014, Vol. 9 (1), e85681. DOI: 10.1371/journal.pone.0085681

22. Pettigrew T. F., Tropp L. R. A meta-analytic test of intergroup contact theory. Journal of Personality and Social Psychology, 2006, Vol. 90 (5), pp. 751-783. DOI: $10.1037 / 0022-3514.90 .5 .751$

23. Visintin E. P., Voci A., Pagotto L., Hewstone M. Direct, extended, and massmediated contact with immigrants in Italy: their associations with emotions, prejudice, and humanity perceptions. Journal of Applied Social Psychology, 2017, Vol. 47, pp. 175-194. DOI: $10.1111 /$ jasp.12423

24. Willis G. B. Cognitive interviewing: A tool for improving questionnaire design. Thousand Oaks, CA: Sage Publications, 2004. 335 p.

25. Rosseel Y. lavaan: An $R$ Package for Structural Equation Modeling. Journal of Statistical Software, 2012, Vol. 48, pp. 1-36. DOI: 10.18637/jss.v048.i02

26. van de Schoot R., Lugtig P., Hox J. A checklist for testing measurement invariance. European Journal of Developmental Psychology, 2012, Vol. 9, pp. 486-492. DOI: 10.1080/17405629.2012.686740

27. Robinson C. D., Tomek S., Schumacker R. Tests of moderation effects: Difference in simple slopes versus the interaction term. Multiple Linear Regression Viewpoints, 2013, Vol. 39, pp. 16-25. 
28. Hayes A. F. Introduction to mediation, moderation, and conditional process analysis: a regression-based approach. New York, NY: Guilford Press, 2013. $494 \mathrm{p}$.

29. Trickett E., Persky I., Espino S. Acculturation research: Proxies as sources of concept obfuscation. In: A. Gari, K. Mylonas (eds.) Quod Erat Demostrandum: From Herodotus' ethnographic journeys to cross-cultural research. Athens, Greece: International Association for Cross-Cultural Psychology, 2009, pp. 267-277. 